\title{
Specular Reflections: John Brett and the Mirror of Venus
}

\author{
James Mussell
}

\begin{abstract}
I now ask leave to add one more suggestion, as follows: - At the next transit it would be worth while for someone with a good telescope and a Dawes-diaphragm to look at the centre of Venus's disk for the reflected image of the Earth. If the envelope of the planet has great refractive power, I think it not improbable that it might be seen as a minute nebulous speck of light. ${ }^{1}$
\end{abstract}

One of the most important nineteenth-century spaces was astronomical space. Nineteenth-century astronomy had a large popular following and many of its leading practitioners were gentlemen amateurs, often of substantial independent means. ${ }^{2}$ At once accessible and distant, familiar yet strange, this space was open to all and there was a thriving market for popular books, periodicals, and astronomical instruments. However, towards the end of the century, the science became increasingly specialized and professionalized. In what follows, I relate a minor incident in the history of astronomy that nonetheless reveals how astronomical authority was constructed in the period. In January 1877 , the painter and astronomer John Brett read a paper to the Royal Astronomical Society (RAS) that suggested Venus might consist of a ball of molten metal enclosed within a layer of glass. ${ }^{3}$ Brett's unlikely theory was based on the light he saw reflected from the planet, which he argued was consistent with specu-

My thanks to John Holmes, Isobel Armstrong, and the referee for 19 who all read drafts of this paper. I would also like to record my thanks to Victoria Osborne, who first directed me towards Edward Burne-Jones's Mirror of Venus.

${ }^{1}$ John Brett, 'The Specular Reflexion Hypothesis and Its Bearing on the Transit of Venus', Monthly Notices of the Royal Astronomical Society, 37 (1877), 126-27 (p. 127).

2 Allan Chapman, The Victorian Amateur Astronomer: Independent Astronomical Research in Britain, 1820-1920 (Chichester: Wiley, 1998); John Lankford, 'Amateurs versus Professionals: The Controversy over Telescope Size in Late Victorian Science', Isis, 72 (1981), 11-28.

3 'Royal Astronomical Society', Astronomical Register, 15 (1878), 25-38. Articles bearing this title are reports on the previous meeting of the Society. 
lar reflection. For Brett, specular reflection offered two visual possibilities. Firstly, it suggested a model for the constitution of the planet, making the inaccessible tangible. Secondly, and more tantalizing still, the reflected image on the surface of Venus offered the seductive possibility of viewing earth from space, seeing it as a planet for the first time.

Brett was a landscape painter, whose early work had been supported by Ruskin and had come to wider notice as part of the Pre-Raphaelite Brotherhood's group exhibition in London in 1857. By the 1870 , Brett had become well known for his large seascapes, which, with their close attention to geological detail and meteorological conditions, achieved a hyperrealistic representation of coastal scenery. Brett had become interested in astronomy as a boy, buying his first telescope at thirteen or fourteen and then building his own at sixteen or seventeen. ${ }^{4} \mathrm{~A}$ keen observer, expert draughtsman, and possessing knowledge of optics, Brett was well suited to astronomy at a time when the science was predominantly observational and the sketch still carried significant evidentiary value. However, spectroscopy and photography complemented direct observational work by producing their own objects of study; observatories were increasing in size, becoming complex institutions with paid staff; and photographic reproduction meant that the mediating influence of the draughtsman and engraver were coming under renewed scrutiny. ${ }^{5}$ In the 1870 , Brett's presence in the institutional space of the RAS made him a target for those seeking to redefine what (and who) constituted astronomical authority.

By turning Venus into a mirror, Brett troubled the institutional space of the RAS, leading his critics to question whether he had a right to be there. Yet his image found a counterpoint in a different institutional space, located not far away from the RAS's rooms in Piccadilly. In May, the opening of the Grosvenor Gallery in fashionable New Bond Street es-

4 'Report of the Council to the Eighty-Second Annual General Meeting of the Royal Astronomical Society', Monthly Notices of the Royal Astronomical Society, 62 (1902), 219-322 (p. 238); Christiana Payne, fohn Brett: Pre-Raphaelite Landscape Painter (New Haven: Yale University Press, 2010), p. 11.

${ }^{5}$ For more on the shifts in astronomical authority in the nineteenth century, see James Mussell, Science, Time and Space in the Late Nineteenth-Century Periodical Press (Aldershot: Ashgate, 2007), pp. 27-6o; Alex Soojung-Kim Pang, Empire and the Sun: Victorian Solar Eclipse Expeditions (Stanford: Stanford University Press, 2002), and 'Victorian Observing Practices, Printing Technology, and Representations of the Solar Corona (1): The 1860 s and 1870s', fournal for the History of Astronomy, 25 (1994), 249-74. 
tablished Edward Burne-Jones's reputation as the leading artist of his day. ${ }^{6}$ Burne-Jones contributed eight pieces to the Grosvenor, the largest of which was his Mirror of Venus (Fig. 1). In a review of the exhibition, Henry James celebrated Burne-Jones's contribution and picked out his Mirror in particular as emblematic of the emerging aesthetic movement. ${ }^{7}$ Although both Brett and Burne-Jones were associated with Pre-Raphaelitism, Brett's meticulous landscapes, which adhered to Ruskin's dictum of 'truth to nature', were far removed from Burne-Jones's paintings, which eschewed the real for the fantastic and symbolic. ${ }^{8}$ Brett's aesthetics seemed to elide the artist, reducing him to a mirror that merely reproduced the scene. Whereas Brett's landscapes suggested that anyone standing in front of them would witness the same scene as that of the artist on the spot, offering an impersonal and interchangeable view, Burne-Jones's Mirror represented the narcissistic gaze and implicated the viewer in its pleasures. In a curious transposition, Brett's speculation on the floor of the RAS reproduced the spatial poetics of Burne-Jones's painting, reflecting back the viewing subject, rather than those that structured his own landscapes.

${ }^{6}$ Georgiana Burne-Jones, Memorial of Edward Burne-fones (London: Macmillan, 19o6), p. 75; Christopher Wood, Victorian Painting (London: Weidenfeld \& Nicolson, 1999), p. 161.

${ }^{7}$ Henry James, 'The Picture Season in London', Galaxy, 24 (1877), 149-61 (p. 157).

${ }^{8}$ Modern Painters, in The Works of Fohn Ruskin, ed. by E. T. Cook and Alexander Wedderburn, Library edition, 39 vols (London: Allen, 1903-12), III, 204, 617. Ruskin preferred the wording 'truth of nature'. See pp. 138-39 and chapter 2, 'That the Truth of Nature is Not to be Discerned by the Uneducated Senses', pp. 14048 . 


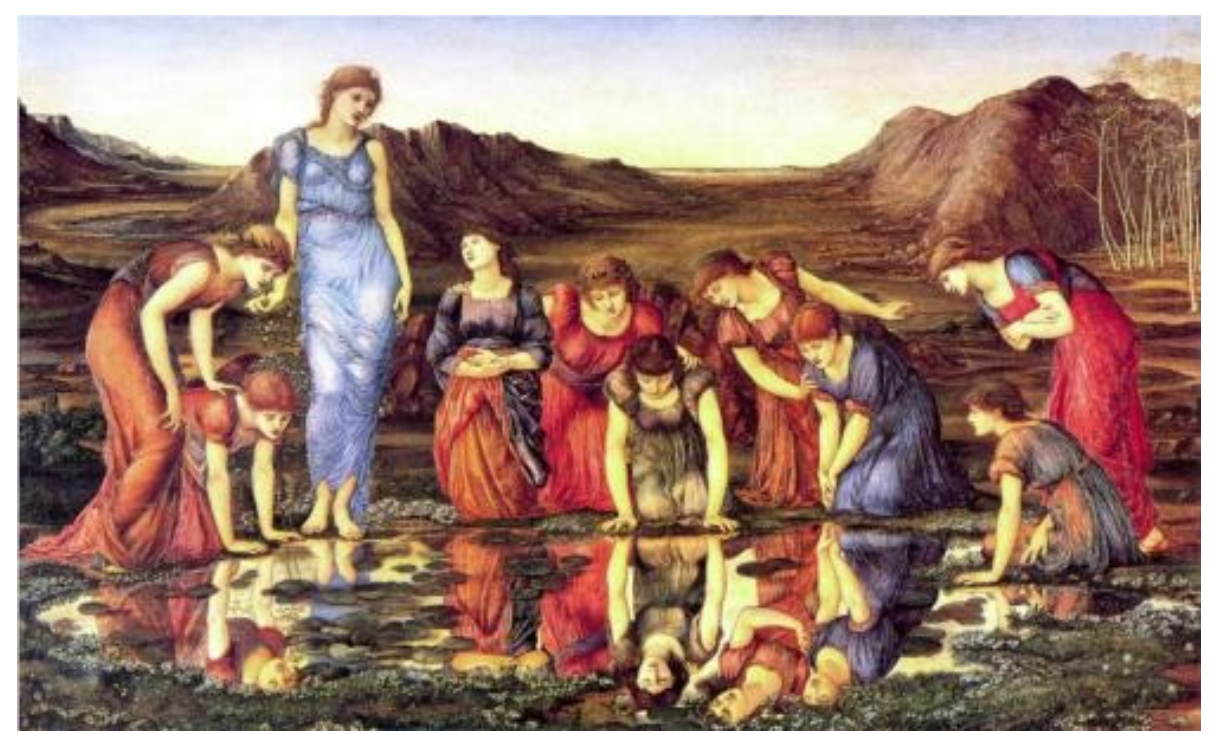

Fig. 1: Edward Burne-Jones, The Mirror of Venus, 1875. Museu Calouste Gulbenkian, Lisbon.

\section{Reflections}

Brett's short paper, 'The Specular Reflexion Hypothesis and its Bearing on the Transit of Venus', published in the Monthly Notices of the Royal Astronomical Society in January 1877 , attempted to account for some unexplained phenomena observed during the transit of 1874. During the transit, a ring of light was seen around Venus that was brighter than the light from the sun. Brett had his own pet theory about Venus that rested upon a patch of light that he had observed on the surface of the planet. Brett argued that this light was the result of specular reflection and so the surface of the planet must be made from some sort of reflective material. ${ }^{9}$ Brett used the theory of specular reflection to account for the change in the size of the ring during transit. For Brett, this was proof of the existence 'of a refractive envelope of atmosphere', magnifying light directly from the sun and reflected from the surface of the planet ('Specular Reflexion', p. 127). Brett writes:

\footnotetext{
${ }^{9}$ For a definition of specular reflection, see John Brett, 'The Functions of Texture in the Arts', Art fournal, April 1893, pp. 117-20 (p. 119).
} 
If there are no theoretical objections to the planet's surface existing in a state of fusion, or at all events, to have so existed, it is not unreasonable to suppose that the metallic constituents of its substance would settle at a lower level than its lighter or vitreous elements: we might thus imagine a molten metallic lustrous surface overlaid and protected by an envelope of glass. (p. 127)

Such a constitution would account for both the patches of light that Brett claimed to have observed on the surface of the planet and the ring of light seen during transit. It also offered the possibility that Venus could act as a mirror, reflecting light back to earth.

Brett's theory of specular reflection raised the tantalizing possibility of viewing the earth from space. If, as Brett suggested at the conclusion of his paper, the reflected image of the earth could be seen in Venus's disk, the earth would be seen, for the first time, as a bounded object, a perspective only possible from an extraterrestrial vantage point. In Brett's model, Venus functioned as a Lacanian mirror, offering an alienated image of the earth as a new form of planetary ego. According to Lacan, the seductive wholeness of the reflected image is complemented by its separateness; the subject, Lacan writes, 'captive to the lure of spatial identification', reconciles the emerging self to an other clad in the 'armour of an alienating identity'. ${ }^{10}$ In the Lacanian mirror stage the otherness of the reflected image offers a fantasy of coherence that requires a defence against the desires that trouble its boundaries. Its otherness also situates the self in the external world of social relations, placing it in a complex play of sameness and difference that associates it with other images while individuating it further. On the planetary scale the earth becomes other, able to be conceived as a whole but also as something separate from the spaces of everyday life. From this vantage point all forms of cultural difference disappear, enclosed within the hemisphere of the planet; however, this vantage point is a fantasy, an atopic space that erases the subjectivity of the viewer. ${ }^{11}$ Brett's invocation of the mirror of Venus in the masculine space of the RAS offered an image of impersonal, objective spectatorship that was, nevertheless, laced with narcissistic desire.

\footnotetext{
${ }^{10}$ Jacques Lacan, 'The Mirror Phase as Formative of the Function of the I', New Left Review, $5^{1}$ (1968), 71-77 (p. 74).

${ }^{11}$ See, for instance, the discussion of the 'blue marble' image taken from Apollo 17 in 1972 .
} 
Brett first brought his theory of specular reflection to the Royal Astronomical Society in May $1876 .^{12}$ He claimed that the distribution of light on the planet's disc indicated that 'the surface of Venus must be in a molten or vitrified state', sketching the patches on the blackboard for the benefit of the other Fellows (p. 132). Both his conclusions and the evidence upon which they rested were immediately contested. William Lassell stated he could not confirm Brett's observations even though he had 'looked through the same telescope, and at the same time, and under precisely the same circumstances' (p. 132). From the Chair, the President of the RAS, William Huggins, reminded the Fellows that 'Mr Brett is an artist', an ambiguous comment that might have offered support for Brett's skills as an observer and draughtsman, but more likely underscoring the difference between Brett and respected amateur astronomers such as Lassell and himself. William Christie, Chief Assistant at the Royal Observatory and soon to become Astronomer Royal, came to Brett's aid. Christie and Brett were known to be friends but Christie, unsurprisingly, defended him on scientific grounds. 'I have no pretensions to be an artist', Christie began, before claiming that he had seen similar marks two years previously: as this observation had been made without 'any special reference to any theory' and was offered 'simply as a matter of fact', Christie hoped his testimony 'may be of the more value', displacing Brett's conclusions with his own scientific credentials (p. 132).

Anything Brett presented would be controversial as he was associated with a particular clique within the RAS. The preparations for the eclipses in 1870 and 1871 and the transit in 1872 had been marred by increasing conflict: attempts were made to raise funds from the state for each and this, exacerbated by scientific differences, led to repeated allegations of jobbery. Things came to a head in the summer of 1872 when Lieutenant Colonel Alexander Strange proposed that the RAS advance plans for a Solar Physical Laboratory to the Royal Commission on Scientific Instruction and the Advancement of Science. Opposition to the plans was led by Richard Anthony Proctor, a prolific and popular astronomer and accomplished controversialist. ${ }^{13}$ Proctor argued that the plans were merely

\footnotetext{
12 'Royal Astronomical Society', Astronomical Register, 14 (1877), 125-36 (p. 132).

${ }^{13}$ For more detailed discussion of the significance of Proctor, see Bernard Lightman, Victorian Popularizers of Science: Designing Nature for New Audiences (Chicago: University of Chicago Press, 2007), pp. 295-351, and 'Knowledge Confronts Nature: Richard Proctor and Popular Science Periodicals', in Culture and Science in the Nineteenth-Century Media, ed. by Louise Henson and others (Aldershot: Ashgate, 2004), pp. 199-210.
} 
an attempt to secure a position for J. Norman Lockyer, the editor of $\mathrm{Na}$ ture, currently serving as Secretary to the Commission. In November 1872, Lockyer, Strange, and Warren De La Rue resigned from the Council of the RAS in protest at the way the plans had been opposed. The nomination of both Lockyer and Proctor for the Society's Gold Medal ensured that the controversy continued into 1873 , reaching its culmination in a stormy election in February. Later that year, Proctor himself resigned from the Council, having openly criticized the Astronomer Royal's plans for the transit in a special number of the Monthly Notices, which he was then editing. ${ }^{14}$ Proctor subsequently stayed away from the meetings of the RAS, but remained an outspoken critic of what he saw as a self-interested clique connected to Lockyer and South Kensington. Brett was on friendly terms with Lockyer, having travelled with him to Sicily to observe the eclipse in 1870, and Lockyer was one of Brett's sponsors when he was elected a Fellow of the RAS in 1871 (Payne, pp. 110-11). For Proctor, Brett was not only a representative of the South Kensington faction, but his position on the Council of the RAS was solely a result of their influence.

In Proctor's absence, the most persistent opponents of Brett's views were Arthur Cowper Ranyard and Captain William Noble. Ranyard, currently serving as Secretary of the RAS, had links with both factions and negotiated the politics of the Society carefully. ${ }^{15}$ Rather than challenge Brett's observations, he challenged his optics, suggesting that the phenomena observed might be accounted for without specular reflection and that specular reflection would produce different effects than those observed. ${ }^{16}$ Captain Noble, however, responded in more personal terms. At the subsequent meeting (June 1876), Noble reported that Brett's paper had prompted him to check Venus once again. He sarcastically noted that Brett's 'trained and artistic eye might have detected an appearance which had been previously overlooked by others less specially employed observing form, light and shade' ${ }^{17}$ However, finding that the light reflected on

\footnotetext{
${ }^{14}$ See, for instance, H. P. Hollis, 'The Decade 1870-1880', in History of the Royal Astronomical Society 1820-1920, ed. by J. L. E. Dryer and H. H. Turner (London: Royal Astronomical Society, 1923), pp. 167-211 (pp. 173-85). For an alternative account, see Richard Proctor, 'Of "C.D." and things which are not', English Mechanic and World of Science, 24 (1877), 430-31.

${ }^{15}$ For Ranyard, see James Mussell, 'Arthur Cowper Ranyard, Knowledge and the Reproduction of Astronomical Photographs in the Late Nineteenth-Century Periodical Press', British fournal for the History of Science, 42 (2009), 321-44.

16 'Royal Astronomical Society', Astronomical Register, 14 (1877), 125-36 (p. 133).

17 'Royal Astronomical Society', Astronomical Register, 14 (1877), 149-58 (p. 156).
} 
Venus's disc was uniform, he concluded that 'Venus does not exhibit anything whatever in the shape of specular reflection, and that its apparition in Mr Brett's case must have had its origin either in his instrument or in his eye' (pp. 156-57).

When Brett presented his full paper on specular reflection on 12 January 1877 , its reception followed the established pattern. Two papers from Christie in November and December 1876 had kept Venus under discussion but displaced Brett's theories as to its structure. ${ }^{18}$ Brett not only argued that Venus was made of molten metal suspended within a glass atmosphere, he also brought along a model which demonstrated that such a constitution would produce the optical effects he had observed. Ranyard once again disputed the optical basis of Brett's conclusions and claimed that it was possible to account for the observed phenomena without 'the extraordinary assumption $[\ldots]$ as to a vitreous envelope encasing the planet'. ${ }^{19}$ For Noble, Brett's theory that the 'planet Venus is like a polished globe of quicksilver, surrounded by a shell of glass' was inherently ridiculous: 'It may of course be possible that Venus is a huge thermometer bulb in the heavens', he suggested, 'but we shall require a great deal of evidence to believe such a theory' (p. 32). Christie's contribution defended the theoretical possibility of specular reflection with mathematical optics, but made no reference to the constitution of the planet or its atmosphere. He was also equivocal in his support for Brett, insisting that there remained 'a great deal to be worked out on the subject' and that he 'should be sorry to lay down any positive statements one way or another' (p. 33). Brett had argued that if Venus had a 'burnished reflecting surface' and 'a translucent envelope of great density, all the elements for a complete explanation are at hand' and his accompanying model further underscored the resemblance between planet and thermometer bulb; Christie was careful to limit himself to 'my observations as I have made them' and to keep his discussion in the space of optical theory.

News of Brett's paper had obviously reached Proctor, as he wrote a letter to the Astronomical Register in time for it to be published along with the report of the meeting in February 1877. For Proctor, Brett's paper was an embarrassment to the RAS. 'One is tempted to ask what is coming to

18 'Royal Astronomical Society', Astronomical Register, 14 (1877), 279-93 (pp. 29193); 'Royal Astronomical Society', Astronomical Register, 15 (1878), 1-10 (pp. 8-9); William Noble, 'Specular Reflection from Venus', Astronomical Register, 15 (1878), p. 16 .

19 'Royal Astronomical Society', Astronomical Register, 15 (1878), 25-38 (pp. 30-31). 
the Royal Astronomical Society when such a paper as Mr Brett's', he writes, 'is allowed to be read before a meeting of the fellows':

All that the spectroscope has taught us, all we have learned of meteoric and cometic systems, and of the laws of cosmical evolution, the laws of optics, and in fine the teachings of every department of modern astronomy, seem of no weight whatever with the excellent artist whose paintings of Sicily scenery delighted us a year or so since (Toujours perdix, \&c). ${ }^{20}$

By citing Brett's paintings of Sicily, Proctor alluded to Brett's involvement in the eclipse expedition of 1870 while ignoring his scientific work. ${ }^{21}$ He used Brett to attack Christie, suggesting that his defence of Brett was designed either to poke 'fun at the meeting' or to 'save a friend from ridicule' and hoped that Christie may 'become less Quixotic or his friend less fanciful and better informed' ('Venus's Glass and Mirror', p. 46). At the same time, both Proctor and Noble were using Brett and his theory to attack the RAS more directly in the pages of the English Mechanic, a longrunning weekly with which both were closely connected. Proctor noted that he had seen the list of Fellows up for election to the Council and regretted that neither Noble nor Ranyard were on it while Brett's name remained. For Proctor, Brett,

however excellently representing English art, is associated with observations the reverse of scientific. Gentlemen who can see the solar corona at midday with ordinary telescopes, and can at a glance detect Venus's 'looking-glass', invite re-

\footnotetext{
${ }^{20}$ Richard Anthony Proctor, 'Venus's Glass and Mirror', Astronomical Register, 15 (1878), 45-46 (pp. 45-46).

${ }^{21}$ Brett and Proctor had been involved in a dispute in 1872 while Proctor was acting editor of the Monthly Notices. See Payne, p. 111; John Brett, 'On Certain Phenomena Surrounding the Sun's Limb' and the subsequent untitled note by Proctor (as 'R.A.P.'), Monthly Notices of the Royal Astronomical Society, 32 (1872), 297, 298-300; Richard Anthony Proctor, 'Good-Natured Friends and Ill-Natured Tattle - Nobody's Business - Cock-and-Bull Stories and Mare's Nests - Telescopic Illusions - Formula for Deducing from a Ship's Length Her Captain's Name Mr Dawes's Visual Powers - Stories of Three Black Crows - Seeing Corona Without Eclipse, and Other Cases of Equines Nidification - If Stars Were There, Then There They Still Should Be - Attack on Radiation - Light and Heat - A Man Beside Himself', English Mechanic, 23 (1876), 48o-81 (p. 481).
} 
flections other than specular among men of science, and are out of place in the councils of scientific bodies. ${ }^{22}$

Noble, writing after the meeting where Brett's paper was presented and discussed but before the proceedings were published in the Astronomical Register, suggested that Christie's 'extraordinary knight-errantry' reflects 'great credit upon his personal and social qualities' but 'can scarcely add to his own already high and deserved reputation as an astronomer', concluding that:

If it be necessary to bolster Mr Brett's reputation as an astronomer in order that he may be kept upon the council, it would surely be wiser for his friend to examine his papers before they are brought forward at the evening meetings. I would venture to hint that this might easily be done at their dining club, and would be at once a more worthy and profitable occupation than hatching coup d'etat there, and boasting about them afterwards. Moreover, such a course would no doubt save them much trouble in defending their weaker ally, and it would further save the time of the society, which might certainly, I think, be better expended than it was (according to your report) at the last meeting. ${ }^{23}$

Noble, like Proctor, acknowledged both Christie's scientific credentials and personal qualities, but nonetheless used his defence of Brett to gesture towards an otherwise occulted set of relationships in the RAS. Proctor might jokily suggest that Brett's theory 'invites reflections other than specular among men of science', but in keeping the reflecting surface of

\footnotetext{
${ }^{22}$ Richard Anthony Proctor, 'Perpendiculars from Angles on Sides of a Triangle Centrifugal Force - A Stretcher - Observatory Chiefs - Speed of Eastern Counties Express - Sun-Spots - Council of Astronomical Society', English Mechanic and World of Science, 24 (1877), 451-52 (p. 452).

23 'FRAS' [William Noble], 'Erratum - The Transit Instrument - Deflection of Shot by the Rotation of the Earth - Varley's Stand - Needing Reflection - The Hours of the Day - Cassiopeiæ - Seeing Faint Stars - Planisphere - Catalogues of Stars and Nebulae - Calculating the Sun's Apogee and Perigee', English Mechanic and World of Science, 24 (1877), 478-79 (pp. 478-79). See also Richard Anthony Proctor, 'The Astronomical Society - Venus A Thermometer Bulb - Compulsory Abstinence and Compulsory Good Behaviour Generally - Seventh-Day Rest - Deflection of Projectiles - Gross Carelessness - A Pleasant Reminiscence', English Mechanic and World of Science, 24 (1877), 501-02.
} 
Venus under scrutiny both Proctor and Noble used Brett's theory to reflect back what they understood as the true face of the society.

\section{Refractions}

Venus was in the air in 1877 and Brett's astronomical speculations found a surprising analogue in another Venus, this one hung on the walls of the newly opened Grosvenor Gallery. Edward Burne-Jones provided eight works for the inaugural hang. These were positioned together on the south wall with the three large canvases, of which The Mirror of Venus was one, hung on the line. The Grosvenor's policy of grouping works by particular artists, taking care over arrangement, illumination, and spacing, meant that it had the potential to considerably enhance the profile of its contributors. Burne-Jones had not exhibited for seven years, adding, as Henry James noted, to 'a certain air of mystery which had long surrounded him'. ${ }^{24}$ He was identified as a representative of an aesthetic school that took fantastical and mythological matter as its subject. Oscar Wilde, for instance, described Burne-Jones as 'a dreamer in the land of mythology, a seer of fairy visions, a symbolical painter' ${ }^{25}$ For James, Burne-Jones's art was that

of culture, of reflection, of intellectual luxury, of aesthetic refinement, of people who look at the world and life not directly, as it were, and in all its accidental reality, but in the reflection and ornamental portrait of it furnished by art itself in other manifestations; furnished by literature, by poetry, by history, by erudition. ('Picture Season', p. 157)

In the Mirror of Venus, James saw a metaphor for aestheticism more broadly:

One of Mr. Burne-Jones's contributions to the Grosvenor is a very charming picture entitled Venus's Mirror, in which a dozen young girls, in an early Italian landscape, are bending over a lucid pool, set in a flowery lawn, to see what I sup-

\footnotetext{
${ }^{24}$ James, 'Picture Season', p. 157. For more on Burne-Jones and the Grosvenor, see Penelope Fitzgerald, Edward Burne-fones: A Biography (London: Joseph, 1975), pp. $165-70$.

${ }_{25}$ Oscar Wilde, 'The Grosvenor Gallery', Dublin University Magazine, July 1877, pp. $118-26$ (p. 118).
} 
posed to be the miraculously embellished image of their faces. Into some such mirror as this the painters and poets of Mr. Burne-Jones's turn of mind seem to me to be looking; they are crowding around a crystal pool with a flowery margin in a literary landscape, quite like the angular nymphs of the picture I speak of. (p. 157)

Just as the women in the painting have their reflections embellished and returned to them (in James's reading) - this difference prolonging the desire to gaze - so James's 'painters and poets' use their imaginations to embellish their vision and create their art. James's analogy thus contains a dense set of reflections: in the case of the Mirror of Venus, the painting is a result of inward reflection; it represents an act of reflection in its depiction of the women gazing into the pool; and, although its painted surface diffuses rather than reflects light (it is what Brett calls a 'granulated' surface), it constitutes a perceptible object that, in turn, prompts further internal reflection in the viewer (Brett, 'Function of Texture', p. 118).

Despite their shared origins in Pre-Raphaelitism, the emergence of aestheticism marked a distinct break with Brett's artistic practice. Nonetheless, it is possible to read Burne-Jones's painting as a version of Brett's Venus. With its circular reflecting pool - 'a mirror of polished steel', according to Wilde ('Grosvenor Gallery', p. 123) - and its 'flowery margin', the painting reproduces the molten surface and glass envelope of Venus posited by Brett (James, 'Picture Season', p. 157). The repetition of the women across the plane of the painting constitutes a transit, with the eye following the line between the women and their reflections. The standing figure of Venus marks a moment, a temporal event that gestures to a before and after while breaking up the pattern of reflection established by the series of stooping women. ${ }^{26}$ Her position breaks the stasis of repetition, much like the way different astronomical cycles - the two transits, for instance - create linear time. Even the landscape, studded with mountains and read as Italian by James and Greek by Sidney Colvin, offers a sufficiently blank contrast to the highly stylized figures to be taken to represent space itself. ${ }^{27}$

\footnotetext{
${ }^{26}$ Kate Flint, 'Edward Burne-Jones's The Mirror of Venus: Surface and Subjectivity in the Art Criticism of the 1870s', in After the Pre-Raphaelites, ed. by Elizabeth Prettejohn (Manchester: Manchester University Press, 1999), pp. 152-64 (p. 152). ${ }^{27}$ James, 'Picture Season', p. 157; Sidney Colvin, 'The Grosvenor Gallery', Fortnightly Review, June 1877, pp. 820-33 (p. 827).
} 
However, it is in its meditation on reflection that the Mirror of Venus informs Brett's astronomy. Christopher Wood has argued that in the Mirror 'narrative and historical content are both almost completely eliminated; this is a truly "subject-less" aesthetic picture' (Victorian Painting, p. 162). Yet, as Kate Flint has argued, its subject is clearly reflection and, precisely because of its engagement with aestheticism, imbricates the viewer into its discourse (pp. 152-54). Flint contrasts the representation of viewing within the painting with the phenomenological experience of spectatorship. As she notes, the women who gaze into the pool make sense of their reflected other by situating it within a pre-existing set of social categories structured by gender (p. 152). The women identify with the alienated model of femininity reflected in the pool and the partial reflections visible to the viewer mark this misrecognition of the reflected self. However, they also serve to refract the gaze of the viewer towards the bodies of the gazing women. This objectification is no surprise, and the hegemonic masculine gaze of the nineteenth-century viewer was accustomed to read the feminine body as beautiful surface. For Martin Danahay, the Mirror of Venus was one of many works from the period that used the figure of a woman gazing at her reflection as a way of shoring up the masculine ego. ${ }^{28}$ By depicting the self-absorbed woman, the male artist could disavow both his own narcissism while also legitimizing the objectified desire represented in the work. Danahay reads such works as versions of the Pygmalion myth, where a masculine desire 'seeks to control female sexuality imaginatively and to define it as naturally monogamous, passive, and reliant upon masculine sexual activity' (p. 44). Such women functioned as (impossible) mirrors, fantasies of reflection that reconciled the contradictions inherent in a masculine desire that needed to identify with its antithesis.

Brett and Burne-Jones knew one another - both men were members of the short-lived Hogarth Club and Burne-Jones and his wife were regularly invited to Brett's studio for his private views ${ }^{29}$ - however, direct influence on the Mirror of Venus is unlikely. Burne-Jones began the painting in 1867 , restarting a new version in 1873 , both prior to the transit of 1874 and long before Brett began advancing his theory of specular reflec-

\footnotetext{
${ }^{28}$ Martin A. Danahay, 'Mirrors of Masculine Desire: Narcissus and Pygmalion in Victorian Representation', Victorian Poetry, 32 (1994), 35-53 (pp. 46-47).

${ }^{29}$ Payne, p. 9o; Martin Harrison and Bill Waters, Burne-fones (London: Barrie and Jenkins, 1989), p. 37 .
} 
tion. ${ }^{30}$ However, by advancing this theory in the masculine space of the RAS, Brett also made use of an idealized and passive femininity to shore up the (middle-class, British) masculine ego. Brett's paper was an invitation for others to replicate his observations, transforming them into evidence for the constitution of the distant planet. Yet his suggestion that the earth might be glimpsed on the surface of Venus unwittingly revealed the institutional basis of this process. The gentlemanly codes of the scientific society underpinned the disinterested rational scientific gaze, generalizing and naturalizing it so that it could stand for all. The supposed femininity of the planet legitimated this gaze while protecting the gaze from itself by putting into play the familiar sexualized dynamic of a masculine science attempting to discover the secrets of nature. This gendered difference ensured that whatever was gazed at remained separate and distinct, a realizable (yet unobtainable) object that could testify to the generalizability of scientific rationality. Such displacements were necessary as the Lacanian mirror stage, with its enforced identification with the other, entails a risk. In reflecting back the astronomical gaze, it might be possible to discern what science necessarily disavows: that the disinterested pursuit of knowledge is also a pleasurable practice sometimes carried out for personal gain. The reflected earth offered a metonym for scientific knowledge, establishing a utopian vantage point that disavowed difference; but it also threatened to reflect back the individual men, interacting (and disagreeing) in specific spaces like the meetings of the RAS.

While Brett's astronomical fantasy might accord with Burne-Jones's aesthetics, his art was markedly different. Throughout the 1870 os Brett had concentrated on producing coastal views, working up large canvases based on sketches produced the previous summer. Brett was committed to a scrupulous representation of landscape, capturing sea, sky, and geological formations with absolute fidelity. He was also committed to situating the viewer of the landscape in space. To mimic binocular vision, for instance, Brett's compositions lacked a detailed foreground and, in order to reproduce the field as seen by human eyes, he worked on canvases twice as wide as they were high (Payne, p. 3). Brett's landscapes allowed the gallery-goer to imagine him or herself as the viewer of the scene, his attention to optical effects reproducing the landscape as if seen from that position under the represented meteorological conditions. Yet to enable such substitutions it was essential that the viewer could be anybody and that

30 Debra Mancoff, 'Unpainted Masterpieces: The Drawings of Edward BurneJones', Art Institute of Chicago Museum Studies, $3^{1}$ (2005), 44-55 (p. 50). 
the artist himself was absent. Brett's landscapes, unlike the mirror of Venus, did not reflect back anything of their viewer.

This curious combination of a hyperrealist representation of landscape with an explicit acknowledgement of human vision produced what many critics felt was a lack in Brett's work. Ruskin's notorious review of Brett's Val d'Aosta (1858) initiated a strain of criticism that haunted Brett throughout his career. Brett had high expectations for Val d'Aosta, an Alpine landscape painted on location between June and November 1858 . His Glacier of Rosenlaui, painted in Switzerland in the summer of 1856 , was praised by Ruskin and established him as a Pre-Raphaelite landscape painter (Payne, pp. 32-35). Ruskin had also praised, pointedly, the landscape elements of his Stonebreaker (1858), wondering in his Academy Notes (1858) what Brett would 'not make of the chestnut groves of the Val d'Aosta! I heartily wish him good speed and long exile' (Ruskin, XIV, 172; Payne, p. 45). The two met in Turin while Brett was painting the Val d'Aosta and continued to be on good terms, Christiana Payne suggesting that Ruskin encouraged Brett to ask a high price for the finished work (p. 5o). However, when he came to review the painting in his Academy Notes of that year, Ruskin tempered his approval by focusing on its mimetic elements. According to Ruskin, 'for the first time in history, we have, by help of art, the power of visiting a place, reasoning about it, and knowing it, just as if we were there' (Ruskin, XIV, 234). In fact, 'standing before this picture is just as good as standing on that spot in Val d'Aosta, so far as gaining of knowledge is concerned' (XIV, 234). Yet the painting is not, 'in the strong, essential meaning of the word, a noble picture':

It has a strange fault, considering the school to which it belongs - it seems to me wholly emotionless. I cannot find from it that the painter loved, or feared, anything in all that wonderful piece of the world [...]. Keenness of eye and fineness of hand as much as you choose; but of emotion, or of intention, nothing traceable $[\ldots]$. I never saw the mirror so held up to Nature; but it is mirror's work, not Man's. (XIV, 236-37)

What Ruskin perceives as an 'absence of sentiment' turns the artist into a mirror, passively reflecting the view and projecting it onto the canvas. That it is 'mirror's work, not Man's' recognizes that not all work is equal, that the traces of Brett's labour that constitute the mimetic reproduction of the scene are not marked in the same way as those that signify some sort of emotional engagement. 'Mirror's work' elides the agency of the artist and makes him or her disappear.

James Mussell, Specular Reflections: John Brett and the Mirror of Venus 19: Interdisciplinary Studies in the Long Nineteenth Century, 17 (2013) <http://19.bbk.ac.uk> 
Similar criticisms continued to be made about Brett's work. In 1873 the Art Journal praised Brett's A Morning Amongst the Granite Boulders, one of two Royal Academy pictures that year, as a 'powerful piece of painting as the exhibition contains' yet found it 'wholly devoid of imaginative significance'. ${ }^{31}$ Brett's talent, according to the critic, is indisputable, but this made the lack in his art even more explicit:

There is no trace of human sensibility, no suggestion that the scene so clearly realised has influenced the mind of the painter. All that is shown is the scene itself, untouched and unchanged, and suggesting no human passion save a passion for mechanical fidelity. (p. 236)

This emphasis on mechanical reproduction was aligned with the mirror in a review of Brett's work at the Royal Academy the following year. In the Pall Mall Gazette, J. Comyns Carr described Brett's Summer Noon in the Scilly Isles as 'a marvellous piece of imitative landscape, wherein every smallest fact has been conscientiously observed and painted with almost complete success so far as perfect illusion can be accounted pictorial success'. ${ }^{32}$ Carr's review argued that modern landscape painters privileged the imitative over the creative, failing to subject their representations of the natural world to a broader aesthetic organization that would allow them 'to interpret the secrets of its beauty'. Brett's art was cited as the most fully realized of this tendency, his choice of tint and texture allowing the work to approach 'as near as possible to reality' (p. 11). For Carr, who would become co-director of the Grosvenor Gallery three years later, the painting

reproduces the features of a scene that has evidently fascinated $\mathrm{Mr}$ Brett, without disclosing in what way the influence of nature has been felt, and thus it does not yield to us any higher or different impression than would be given by the scene itself. (p. 11)

The surface of the canvas recorded the labour required to create the image - Ruskin described the Val d'Aosta as a 'wonder of toil and delicate handling' and Carr notes the 'fine patience and splendid industry' that creat-

31 'Exhibition of the Royal Academy', Art fournal, August 1873, pp. 236-41 (p. 236).

32 [J. Comyns Carr], 'The Royal Academy (concluding article)', Pall Mall Gazette, 3o June 1874, pp. 10-11 (p. 11). 
ed Summer Noon in the Scilly Isles - but if it did not also record some sort of sentiment, reflecting back the emotion of the artist, then the traces of this work became sublimated in the overall mimetic effect (Ruskin, XIV, 234; [Carr], p. 11). As Carr concludes, the 'scene has passed through no process of digestion before it appears on the canvas; and the artist's vision is like a mirror, reflecting without change the facts presented upon it' (p. 11). If both painting and painter simply reflect the view, then the distinction between each is effaced and they both become part of the same reflecting surface.

When the artist is a mirror, he or she becomes a model of disinterested observation, part of the necessary media that move and fix the image. Brett's art thus achieves and mobilizes what would be, in another context, the objective disembodied gaze of science. Yet in the scientific space of the Royal Astronomical Society he proposed a theory that troubled the ideological and institutional basis of scientific practice. By suggesting that the surface of Venus might reflect the earth, Brett raised both the possibility of realizing the generalizable scientific gaze and its other, a reflected image of the gazing scientist. Yet Brett was not able to convince other astronomers that what he saw on the surface of Venus was evidence of reflection. Brett's art may have been criticized, especially by those critics sympathetic to aestheticism, because it lacked emotional content, failing to reflect anything of the artist (except, perhaps, his labour), but his science was criticized because it revealed too much of Brett. By failing to prove that what he saw was the same as what other astronomers also saw, thus generalizing the space of scientific practice, Brett's observations attested to his desire to prove his theory, rather than constituting evidence that might support it.

\section{Conclusions}

I ask leave only to add one more suggestion and that is that at the next transit it would be worthwhile for someone with a good telescope and Dawes diaphragm to look at the centre of Venus's disc for the reflection of the earth - for if the envelope has great refractive power I think it not improbable that the image of the earth may be seen reflected there as a minute nebulous speck light. [laughter] $]^{33}$

\footnotetext{
33 'Royal Astronomical Society', Astronomical Register, 15 (1878), 25-38 (p. 29).
} 
The account of Brett's paper in the Astronomical Register differs slightly from that published in the Monthly Notices of the Royal Astronomical Society that I quoted as the epigraph at the start of this article. The most important difference is the record of the audience's reaction to his paper: '[laughter]'. Given the discussion that followed, the audience were not laughing at Brett, but instead recognized the fanciful nature of his proposal. What was at stake was whether or not the bright patches on the planet were due to specular reflection: if they were, then there might be grounds for Brett's broader theories as to the constitution of the planet. The laughter indicates that both Brett and his audience knew that the possibility of viewing the reflected earth was a fantasy. The laughter puts the reflected earth into parenthesis, marking it as something not to be taken seriously, unlike the possibility of the reflective surface of Venus, which could be contested on astronomical or optical grounds. Nonetheless, Brett did make the suggestion and, even if presented as a joke, it was a suggestion that exposed the disavowed narcissism on which it was based. Likewise, Danahay claims that Burne-Jones 'intends to evoke a self-referential desire in the male viewer' and that the Mirror functions 'as the basis for a narcissistic reverie' (p. 47). However, the image troubles its own fantasy. For Wilde, some of the women, 'weary of shadows', no longer gaze at their reflections and, as Flint notes, the standing figure, usually identified as Venus, introduces a before and after into the image (Wilde, p. 123; Flint, p. 152). By at least acknowledging the autonomy of the gazing women, hinting at the existence of a narrative even if it remains untold, Burne-Jones draws attention to the fantasy that underpins such narcissism. Like Brett's joke, Burne-Jones's painting both indulges a particular form of aesthetics and exposes the concealed politics that underpinned it.

The record of the laughter marks an important difference between the two versions of Brett's paper. The report in the Astronomical Register recorded the events at the meeting of the Royal Astronomical Society, including the papers as read, whereas the Monthly Notices published the papers as written and so abstracted from the moment of their first performance. The space of the RAS was mobilized differently in each case: in the Astronomical Register both papers and the subsequent discussion were given; in the Monthly Notices only the papers were provided, usually concluding with an address and date. The Astronomical Register circulated a textualized version of the space of the Society, allowing some sort of access to those excluded, whereas the Monthly Notices elided the events that took place at the meetings and instead turned the Society into a mark of 
authority, warranting the quality of the papers. The absence of the '[laughter]' in the paper published in the Monthly Notices transforms the status of Brett's fantasy, rendering it part of the paper proper.

Brett's interest was not really in the reflected image, but what the fact of reflection might say about the constitution of the planet. Brett needed to transform his contingent observations, made at specific moments with certain configurations of equipment, into generalized facts. To do this, Brett had to elide both his own agency and that of the mediating technology that made the planet visible. In other words, Brett's mirror of Venus needed to function like one of his landscapes, eliding both the work of the artist and the affordances of paint and canvas. Instead, it resembled Burne-Jones's Mirror of Venus, the image directing attention back upon its viewer. Proctor might have indignantly responded to the reading of Brett's paper as reported in the Astronomical Register, but his concerns were to do with Brett's role in the Society as much as they were to do with this science. Brett's mirror tantalizingly offered the chance to view the earth as a whole, collapsing difference into a seductive image of unity. This image could stand as a metaphor for an idealized astronomy and so idealized science, discovering indisputable, essentialized facts about the natural world. Instead, he displaced the reflective surface of the planet with an image that made visible the internal wrangling of the Royal Astronomical Society. In reflecting the astronomical gaze, Brett's mirror revealed both the ideological promise of science and the politics and poetics that underpinned its practice. 